\title{
Perfil de prescrição de antimicrobianos para as infecções do tracto urinário nos cuidados de saúde primários
}

Inês Vilas-Boas Tavares,* Armando Brito de Sá**

\section{RESUMO}

Objectivos: Avaliação do perfil de prescrição de antibióticos para as infecções do tracto urinário (ITU) na Medicina Geral e Familiar e sua concordância com a Norma da Direção-Geral da Saúde (DGS) «Terapêutica das infecções do aparelho urinário (comunidade)». Identificação dos microrganismos infectantes e determinação do seu perfil de sensibilidade.

Tipo de estudo: Estudo transversal, descritivo e observacional.

Local: Unidades de Saúde Familiar da Região de Lisboa e Vale do Tejo, Portugal.

População: Indivíduos com idade igual ou superior a 18 anos com episódios de ITU identificados clínica e/ou laboratorialmente. Métodos: A informação foi recolhida a partir de uma folha de registo de dados por 38 médicos de Medicina Geral e Familiar entre Novembro de 2011 e Janeiro de 2012. Obteve-se uma amostra não aleatória de 104 episódios de ITU de indivíduos com idade igual ou superior a 18 anos. As variáveis estudadas foram as seguintes: sexo, idade, tipo de ITU, pedido de urocultura, antibioterapia baseada no resultado da urocultura, prescrição antibiótica, resultado da urocultura e sensibilidade aos antimicrobianos.

Resultados: A cistite aguda não complicada em mulher não grávida foi o tipo de ITU mais frequente (81,7\%). Em $72,1 \%$ das ITU foi pedida urocultura. Foi prescrito antibiótico em 93,3\% das ITU, sendo a fosfomicina (38,1\%) e a nitrofurantoína (21,6\%) os antibióticos mais prescritos. Nos episódios de cistite aguda não complicada em mulher não grávida verificámos que em $64,2 \%$ o antibiótico prescrito esteve em concordância com a Norma. A urocultura foi positiva em $82,1 \%$ das situações em que este exame foi executado, tendo-se isolado Escherichia coli (E.coli) em 76,1\% destes casos. Não se encontrou nenhum caso de resistência à fosfomicina e à nitrofurantoína.

Conclusões: Na maioria dos episódios de ITU a prescrição de antibióticos foi adequada e concordante com a Norma. A E.coli foi o microrganismo mais frequentemente isolado, apresentando elevada susceptibilidade à fosfomicina e nitrofurantoína.

Palavras-Chave: Infecção do Tracto Urinário; Antibióticos; Resistência Antimicrobiana.

\section{INTRODUÇÃO}

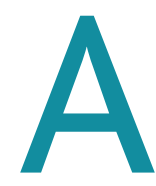

resistência aos antibióticos é um problema de saúde pública que continua a aumentar na Europa. ${ }^{1} \mathrm{O}$ uso desnecessário ou prolongado de antibióticos é o principal factor responsável pela crescente emergência de microrganismos resistentes que num futuro poderá pôr em causa a sua eficácia e utilidade. ${ }^{2}$ As estratégias com maior impacto para a contenção das resistências aos antimicro-

*Médica interna do ano comum, Centro Hospitalar de Lisboa Norte.

**Professor auxiliar convidado, Instituto de Medicina Preventiva, Faculdade de Medicina, Universidade de Lisboa bianos são as que se baseiam no uso racional e adequado de antibióticos, na prevenção e controlo da infecção e em programas de vigilância que avaliem a susceptibilidade dos microrganismos. ${ }^{3}$ A nível internacional têm sido criadas várias iniciativas com a intenção de limitar o aparecimento de resistências, nomeadamente os projectos European Surveillance of Antimicrobial Consumption (ESAC) e o European Antimicrobial Resistence Surveillance System (EARSS), que em conjunto permitem avaliar as tendências actuais de utilização de antimicrobianos e estudar a emergência das resistências na Europa. ${ }^{4-5}$ 
De acordo com os últimos dados internacionais publicados em 2010 pelo ESAC, há grandes diferenças quanto aos padrões de utilização de antibióticos entre os países europeus. ${ }^{4}$ A classe das penicilinas continua a ser o grupo de antibióticos mais prescrito em todos os países da União Europeia. ${ }^{1}$ Em Portugal tem-se verificado uma diminuição do consumo de antibióticos. ${ }^{4} \mathrm{Um}$ estudo publicado na revista Lancet em 2001 referia que Portugal era o país da União Europeia com maior uso de quinolonas. ${ }^{6}$ Dados mais recentes, porém, revelam taxas de uso superiores em Itália, Chipre e Grécia. ${ }^{5}$

Os médicos de família são responsáveis por aproximadamente $80 \%$ das prescrições de antibióticos. ${ }^{7}$ As infecções do tracto urinário (ITU) representam uma causa comum de prescrição de antibióticos em medicina geral e familiar. ${ }^{8-9}$ Em Portugal, a ITU é a segunda patologia infecciosa mais prevalente na comunidade, logo após a infecção do tracto respiratório. ${ }^{10}$

As ITU ocorrem muito mais frequentemente em mulheres. ${ }^{11}$ Estima-se que uma em cada três mulheres terá uma ITU até aos $24 \operatorname{anos}^{12}$ e que 40-50\% das mulheres adultas tenham pelo menos uma ITU em determinada altura da vida. ${ }^{11}$

A instituição precoce de tratamento é a forma mais eficaz de diminuir a morbilidade e a mortalidade associadas às ITU, diminuindo a gravidade da infecção e a probabilidade de disseminação às vias urinárias superiores. ${ }^{13}$

O diagnóstico de ITU baseia-se na história clínica e na sintomatologia do doente mas só é confirmado por urocultura. Apesar de tudo, na maioria dos casos o exame cultural da urina não é necessário. ${ }^{14} \mathrm{O}$ uso de terapêutica empírica está recomendado nas ITU não complicadas. ${ }^{15-17}$

A Escherichia coli (E. coli) é o microrganismo que mais frequentemente causa ITU na comunidade.

Com o aumento progressivo das resistências antimicrobianas a nível mundial, a escolha da terapêutica empírica das ITU tem provado ser um desafio constante. ${ }^{18}$

O conhecimento da realidade epidemiológica e dos padrões de susceptibilidade antimicrobiana dos microrganismos das diferentes zonas geográficas permite uma escolha mais adequada da terapêutica empírica e a limitação da disseminação das estirpes resistentes. ${ }^{17}$

Ao longo do tempo têm surgido vários estudos que confirmam um aumento da resistência aos antimicrobianos comummente usados para tratar as ITU e a variabilidade geográfica destes valores. ${ }^{19-21} \mathrm{O}$ estudo ECO•SENS, realizado em 1999/2000, foi o primeiro programa de vigilância internacional a analisar a prevalência e a susceptibilidade dos patogénios urinários aos antibióticos. Este estudo também observou que o consumo de antibióticos era maior no sul da Europa, nomeadamente em Portugal e Espanha.,22

Os níveis de resistência à amoxicilina e ao trimetroprim-sulfametoxazol reportados na Europa e América do Norte são geralmente superiores a $20 \%$, enquanto que a resistência às fluroquinolonas, cefalosporinas e amoxicilina com ácido clavulânico é na maioria dos locais inferior a $10 \%$. Porém, parece haver uma tendência para a resistência às fluroquinolonas aumentar. A nitrofurantoína e a fosfomicina apresentam boas percentagens de susceptibilidade. . $^{3,17,22}$

Em Portugal, os estudos existentes sobre ITU realizados na comunidade verificaram altas taxas de resistência da $E$. coli às penicilinas, às quinolonas e ao trimetropim-sulfametoxazol. ${ }^{23-24}$ Quanto às cefalosporinas, os estudos apresentam dados discrepantes. ${ }^{23,24}$

No sentido de tentar optimizar a abordagem das ITU, nomeadamente o seu tratamento, têm-se reunido esforços para criar recomendações clínicas. ${ }^{25}$

Vários estudos têm apontado que as orientações são difíceis de implementar pelos clínicos gerais..$^{8-9,26}$ Uma menor adesão às recomendações pode acarretar mais custos em saúde. ${ }^{27}$

Com este propósito, em Agosto de 2011, a Direcção-Geral da Saúde divulgou uma Norma intitulada «Terapêutica de infecções do aparelho urinário (comunidade)» em que apresenta as linhas gerais de abordagem das ITU na comunidade, nomeadamente em relação à terapêutica. $^{28}$

O presente estudo teve os seguintes objectivos:

- Determinar que antibióticos são prescritos em situações de infecção do tracto urinário identificadas clínica e/ou laboratorialmente em utentes seguidos em consultas de Medicina Geral e Familiar;

- Avaliar o grau de concordância entre as prescrições efectuadas e a Norma da Direcção-Geral da Saúde número 015/2011 de 30 de Agosto de 2011: Terapêutica das infecções do aparelho urinário (comunidade) ${ }^{28}$ 
- Identificar os microrganismos infectantes nas situações em que foi efectuada urocultura;

- Determinar o perfil de sensibilidade aos antibióticos dos microrganismos identificados.

\section{MATERIAL E MÉTODOS}

Realizou-se um estudo transversal, descritivo e observacional.

O estudo envolveu a participação de 38 médicos de Medicina Geral e Familiar de cinco Unidades de Saúde da Região de Lisboa e Vale do Tejo (USF Rodrigues Miguéis, USF Parque, USF Tejo, USF Parque da Cidade e UCSP Benfica). Estes médicos foram escolhidos por um critério de conveniência.

A amostra foi obtida por método não aleatório, durante o período de tempo compreendido entre Novembro de 2011 e Janeiro de 2012, sendo constituída por todos os indivíduos com idade igual ou superior a 18 anos com episódios de ITU identificados clínica e/ou laboratorialmente que frequentaram as consultas de medicina geral e familiar dos médicos participantes no estudo.

Após solicitada a sua participação no estudo, a recolha de dados foi feita pelos médicos em folhas de registo de uma forma anónima e confidencial.

A folha de registo de dados (Anexo 2) foi desenvolvida especificamente para este estudo, contendo sete perguntas fechadas com várias opções de resposta e uma pergunta aberta. Um grupo de perguntas tinha como objectivo caracterizar as variáveis demográficas da amostra. O outro conjunto de perguntas incidia sobre as variáveis clínicas específicas do estudo.

Foram estudadas as seguintes variáveis:

- Sexo (feminino, masculino);

- Idade (anos completos);

- Tipo de infecção urinária (cistite aguda não complicada em mulher não grávida, cistite aguda não complicada em mulher grávida, pielonefrite - casos ligeiros a moderados, bacteriúria assintomática em grávidas, bacteriúria assintomática em candidatos a ressecção trans-uretral da próstata (RTU-P), outros);

- Pedido de urocultura (sim, não);

- Antibioterapia baseada no resultado da urocultura (sim, não);

- Primeiro antibiótico prescrito;
- Resultado da urocultura (negativa, microrganismo isolado);

- Resultado do antibiograma.

Foi solicitado aos médicos participantes no estudo que preenchessem uma folha de registo de dados por cada episódio de ITU identificado. O preenchimento dos dados poderia ser efectuado em diferentes circunstâncias: numa só consulta, quando o episódio fosse resolvido (terapêutica empírica sem outro tipo de intervenção); em duas ou mais consultas (início de sintomatologia e regresso para mostrar resultado do antibiograma); retrospectivamente (situações em que o doente traz urocultura).

A folha de registo de dados foi testada durante uma semana, tendo sido reformuladas duas perguntas.

As respostas obtidas foram codificadas e registadas numa matriz inserida em suporte informático e o tratamento estatístico dos resultados foi processado no programa informático Microsoft Office Excel 2007.

O estudo foi aprovado pela Direcção Executiva do Agrupamento de Centros de Saúde de Lisboa Norte.

\section{RESULTADOS}

Durante o período em estudo obtiveram-se 107 relatos de episódios de ITU. Do total de folhas de registo preenchidas três foram excluídas por não existirem registos referentes ao tipo de infecção urinária. A amostra final foi de 104 episódios de ITU.

\section{Sexo e idade}

A caracterização demográfica da amostra por grupo etário e sexo encontra-se na Figura 1.

A média de idades foi de 62,6 anos (desvio padrão 17,9 anos), sendo a mediana de 66,5 e a moda de 65 , com idades compreendidas entre os 23 anos e os 95 anos.

Os indivíduos com idade igual ou superior a 65 anos constituíram $57,7 \%$ do total de episódios de ITU. Noventa e cinco episódios de ITU ocorreram no sexo feminino $(91,3 \%)$ e nove no sexo masculino $(8,7 \%)$. As mulheres apresentaram maior número de episódios de ITU em todos os grupos etários.

\section{Tipo de ITU}

A distribuição por tipo de ITU está representada na Figura 2. 


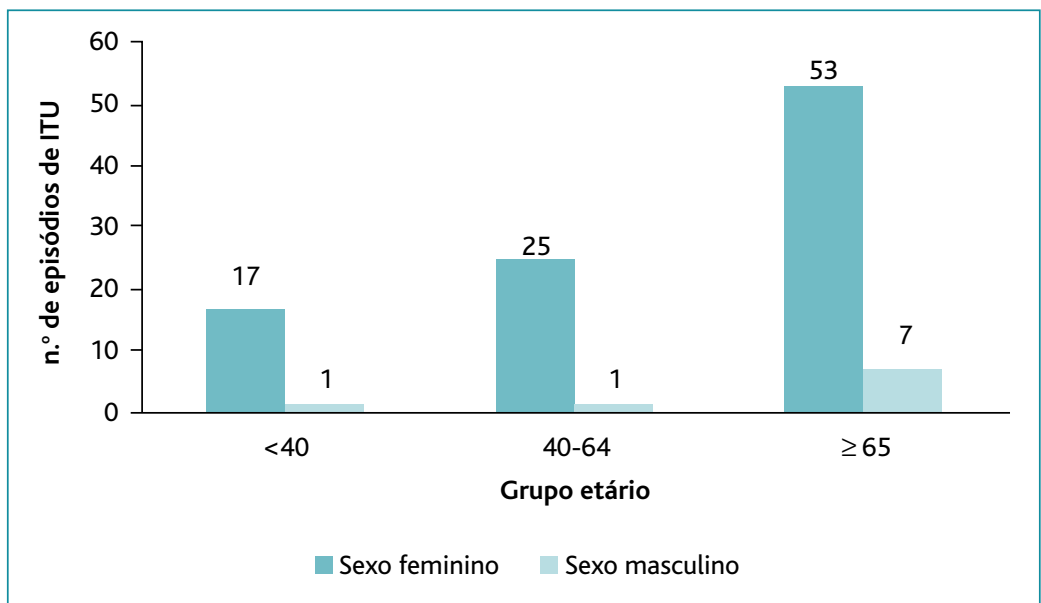

Figura 1. Caracterização da amostra por grupo etário e por sexo $(\mathrm{N}=104)$ tritos positivos no sedimento urinário em mulher (um caso) e lombalgia com Combur positivo em mulher (um caso).

O Quadro I mostra a distribuição das ITU por sexo e tipo de ITU.

Comparando a distribuição do tipo de ITU por grupo etário (Figura 3), verificou-se um maior número de episódios de Cistite Aguda Não Complicada em Mulher Não Grávida no grupo etário dos mais de 65 anos inclusive (46 casos). $\mathrm{O}$ único episódio de Pielonefrite ligeira-moderada relatado ocorreu também neste grupo etário.

\section{Pedido de urocultura}

Foi pedida urocultura em 75 episódios de ITU $(72,1 \%)$, dos quais 67 foram realizados em mulheres $(89,3 \%)$ e oito em homens $(10,7 \%)$.

Em relação às mulheres, 58 pedidos de urocultura corresponderam a episódios de Cistite Aguda Não Complicada em Mulher Não Grávida, sete a episódios Outros, um a Cistite Aguda Não Complicada em Mulher Grávida e um a Pielonefrite ligeira-moderada. Quanto aos homens, todos os oito pedidos de urocultura pertenciam a ITU classificadas como Outros.

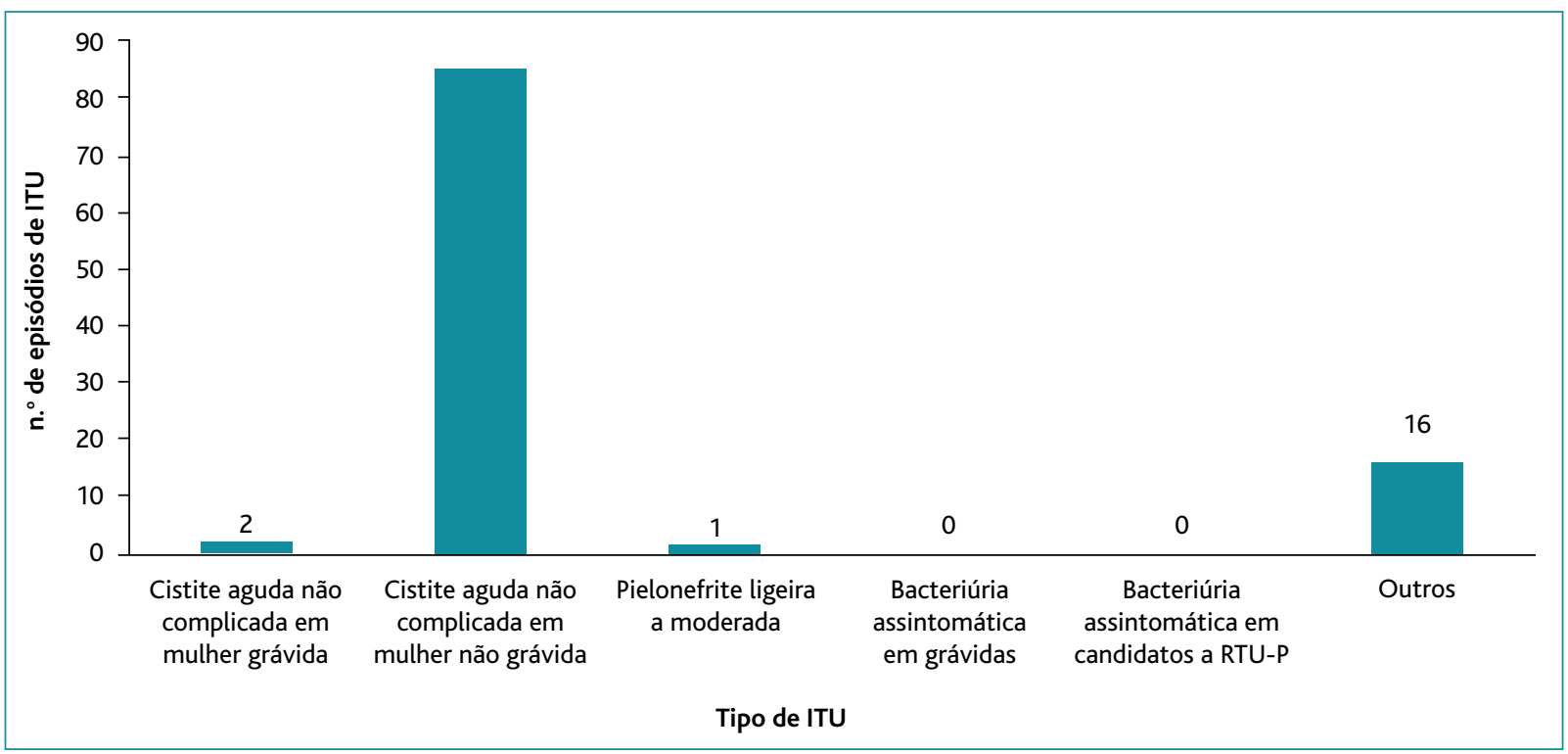

Figura 2. Distribuição das ITU por tipo de ITU $(N=104)$ 


\begin{tabular}{|c|c|}
\hline \multicolumn{2}{|l|}{$\begin{array}{l}\text { QUADRO I. Distribuição das ITU por sexo e tipo de ITU } \\
(\mathrm{N}=104) \text {. }\end{array}$} \\
\hline Sexo/Tipo de ITU & $\mathbf{N}$ \\
\hline Feminino & 95 \\
\hline Cistite Aguda Não Complicada em Mulher Grávida & 2 \\
\hline $\begin{array}{l}\text { Cistite Aguda Não Complicada em Mulher Não } \\
\text { Grávida }\end{array}$ & 85 \\
\hline Outros & 7 \\
\hline Pielonefrite & 1 \\
\hline Masculino & 9 \\
\hline Outros & 9 \\
\hline Total & 104 \\
\hline
\end{tabular}

Observa-se que, nos casos em que não foi pedido o exame, 28 eram mulheres, dos quais um episódio era de Cistite Aguda Não Complicada em Mulher Grávida e os restantes 27 episódios correspondiam a Cistite Aguda Não Complicada em Mulher Não Grávida. O pedido de urocultura não foi realizado num homem, correspondendo a um episódio de ITU classificada como $\mathrm{Ou}$ tros (Quadro 2).

Foram analisadas os pedidos de urocultura e con- frontados com as situações em que a Norma aconselha a sua realização (Figura 4). A urocultura prévia à antibioterapia está indicada na grávida, na idade pediátrica, no homem, nas ITU complicadas ou recidivantes na mulher adulta e na pielonefrite. ${ }^{28}$ Nos casos em que não foi pedida urocultura, esta não concordância com a Norma verificou-se para um episódio de Cistite Aguda Não Complicada em Mulher Grávida e um episódio de ITU em homem. Quando foi pedida urocultura verificou-se que em pelo menos 58 episódios de Cistite Aguda Não Complicada em Mulher Não Grávida não houve concordância com as recomendações.

\section{Antibioterapia}

A escolha do antibiótico não foi baseada no resultado da urocultura em 74 casos $(71,2 \%)$.

A prescrição de antibiótico foi registada em 97 episódios de ITU (93,3\%). Em sete episódios o antibiótico não constava no registo $(6,7 \%)$.

A Figura 5 apresenta as frequências absolutas com que cada princípio activo foi prescrito.

A fosfomicina $(38,1 \%)$ e a nitrofurantoína $(21,6 \%)$ foram os antibióticos mais prescritos. Em 15,5\% episódios foram prescritas penicilinas, as quinolonas representam $14,4 \%$ e as cefalosporinas $3,1 \%$ da amostra. Em

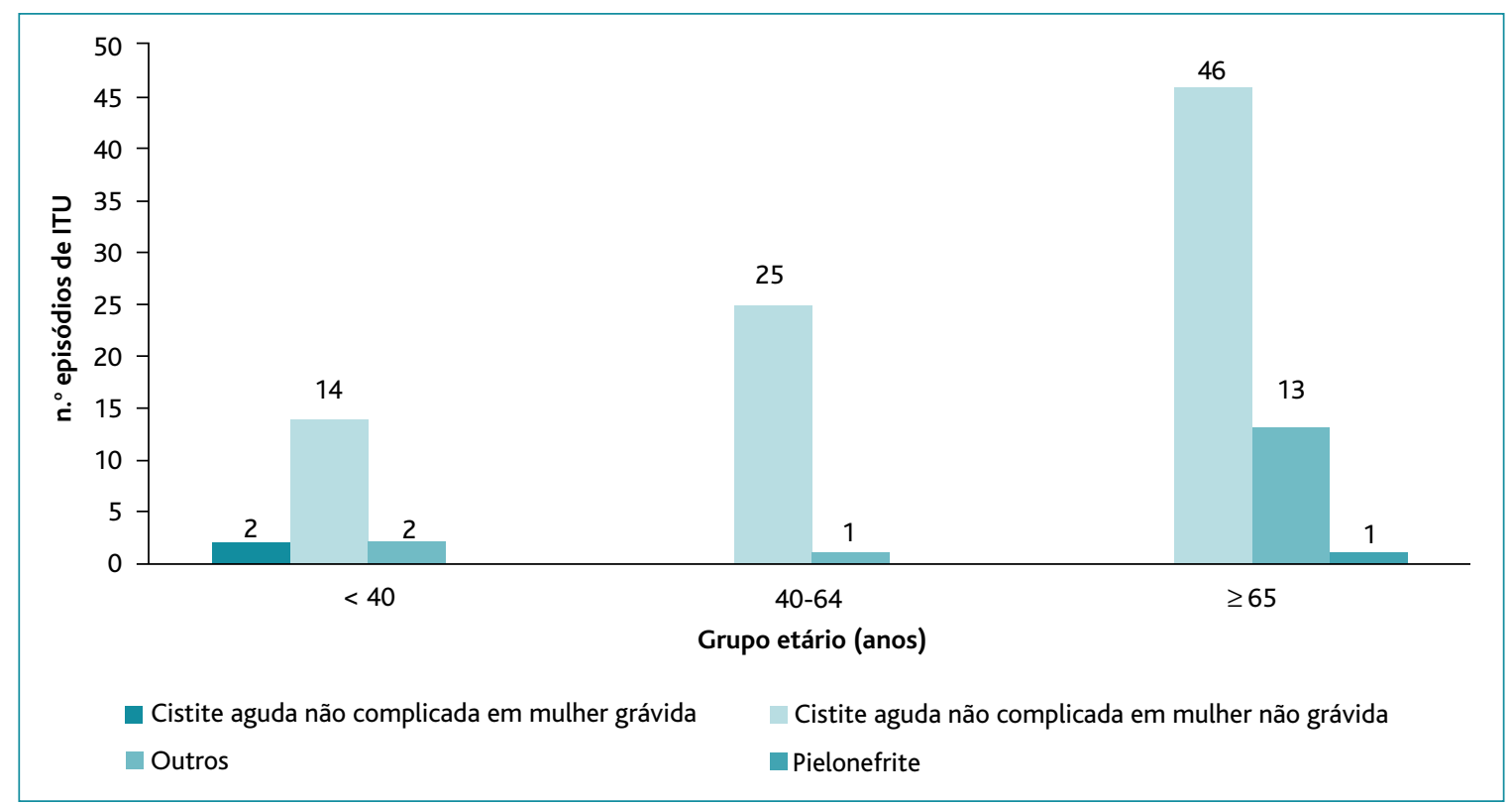

Figura 3. Distribuição do tipo de ITU por grupo etário $(N=104)$ 


\begin{tabular}{|l|r}
\hline $\begin{array}{l}\text { QUADRO II. Distribuição dos pedidos de urocultura por } \\
\text { sexo e tipo de ITU (N=104). }\end{array}$ \\
\hline Episódios de ITU & N \\
\hline Sem pedido de Urocultura & 29 \\
\hline Sexo feminino & 28 \\
Cistite Aguda Não Complicada em Mulher Grávida & 1 \\
Cistite Aguda Não Complicada em Mulher Não & 27 \\
Grávida & \\
\hline Sexo masculino & 1 \\
Outros & 1 \\
\hline Com pedido de Urocultura & 75 \\
\hline Sexo feminino & 67 \\
Cistite Aguda Não Complicada em Mulher Grávida & 1 \\
Cistite Aguda Não Complicada em Mulher Não & 58 \\
Grávida & 1 \\
Pielonefrite ligeira a moderada & 1 \\
Outros & 7 \\
\hline Sexo masculino & 8 \\
Outros & 8 \\
\hline Total & \\
\hline
\end{tabular}

como terapêutica de primeira linha esteve em concordância com a Norma (nitrofurantoína ou fosfomicina). ${ }^{28} \mathrm{~A}$ amoxicilina com ácido clavulânico foi prescrita em oito episódios (9,9\%). Em 21 casos (25,9\%) foram prescritos outros antibióticos que não estão contemplados na Norma como primeira linha.

Nos dois episódios registados como Cistite Aguda Não Complicada em Mulher Grávida o antibiótico prescrito foi a fosfomicina, o que está de acordo com a Norma.

Relativamente ao único episódio de Pielonefrite, o antibiótico instituído foi o trimetropim-sulfametoxazol, o que não é concordante com a Norma.

\section{Resultado da urocultura}

Nas situações em que foi pedida urocultura $(n=75)$, não houve registo do resultado em 19 casos $(25,3 \%)$. Obteve-se o resultado da urocultura em 56 casos $(74,7 \%)$, dos quais em dez a urocultura foi negativa $(17,9 \%)$ e em 46 a urocultura foi positiva $(82,1 \%)$.

A distribuição por resultado da urocultura e por sexo está representada na Figura 8.

Nos exames bacteriológicos positivos foram identificadas seis estirpes diferentes, sendo a E.coli o micror-

7,2\% dos episódios de ITU a escolha incidiu sobre o trimetropim-sulfametoxazol.

Analisando as prescrições de antibióticos respeitantes à Cistite Aguda Não Complicada em Mulher Não Grávida (Figura 6), verifica-se que o antibiótico mais prescrito foi a fosfomicina (40,7\%) seguindo-se a nitrofurantoína (23,5\%).

A terapêutica escolhida pelos clínicos para os episódios de Cistite Aguda Não Complicada em Mulher Não Grávida foi comparada com as recomendações sugeridas pela Norma e está representada na Figura 7.

Em 52 destes episódios $(64,2 \%)$ o antibiótico prescrito

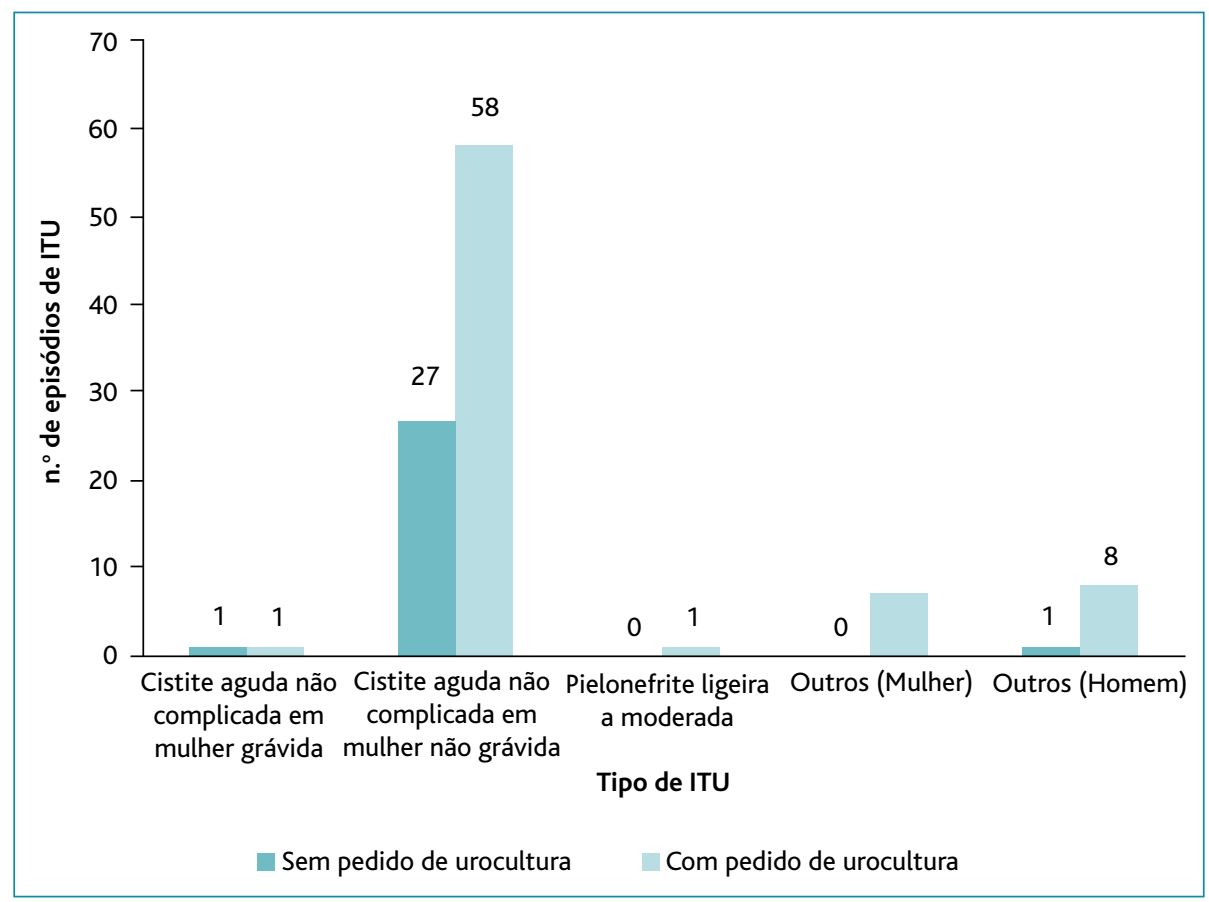

Figura 4. Frequências absolutas das ITU com e sem pedido de urocultura ( $N=104)$ 


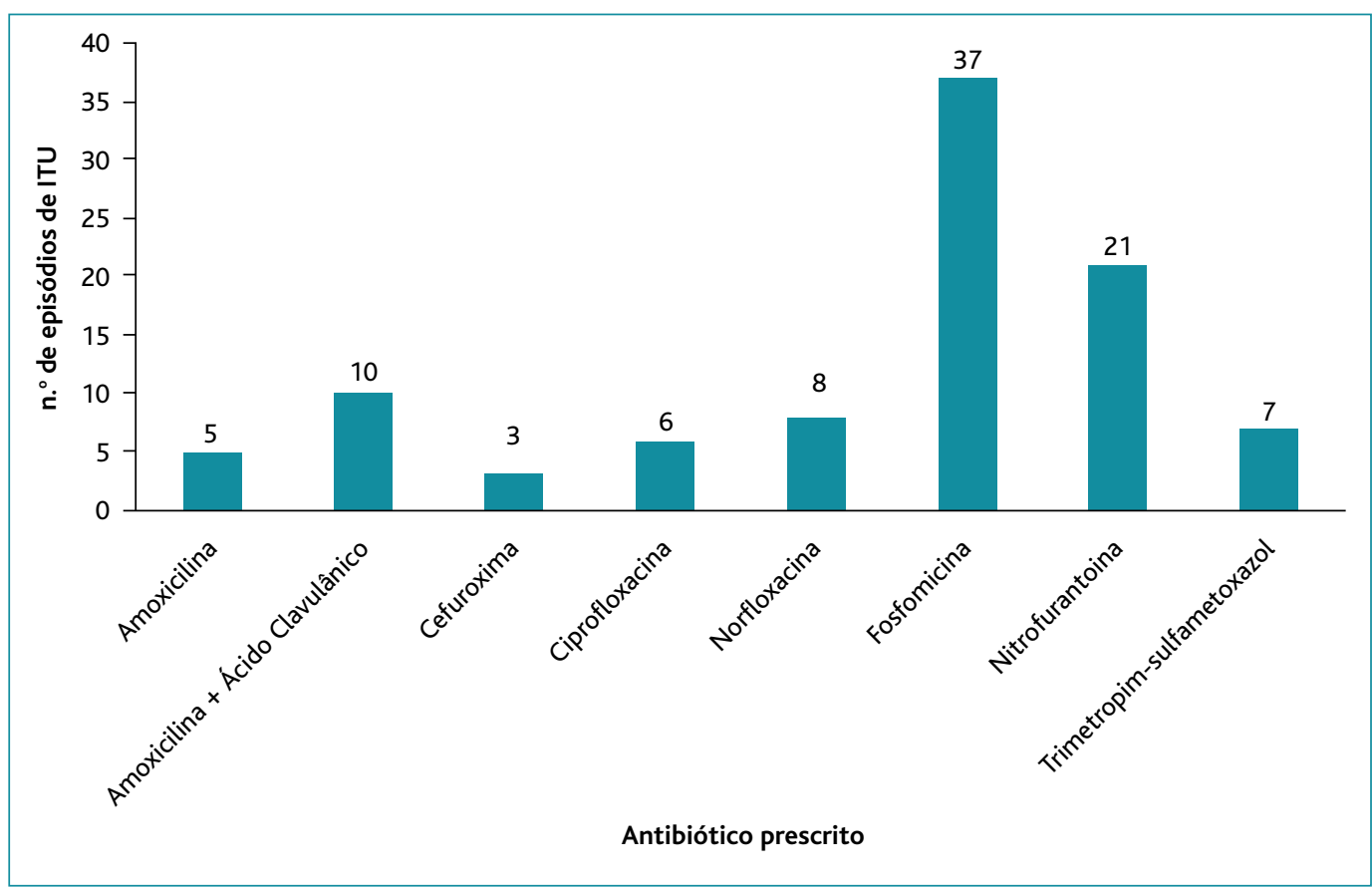

Figura 5. Frequência absoluta de antibióticos prescritos

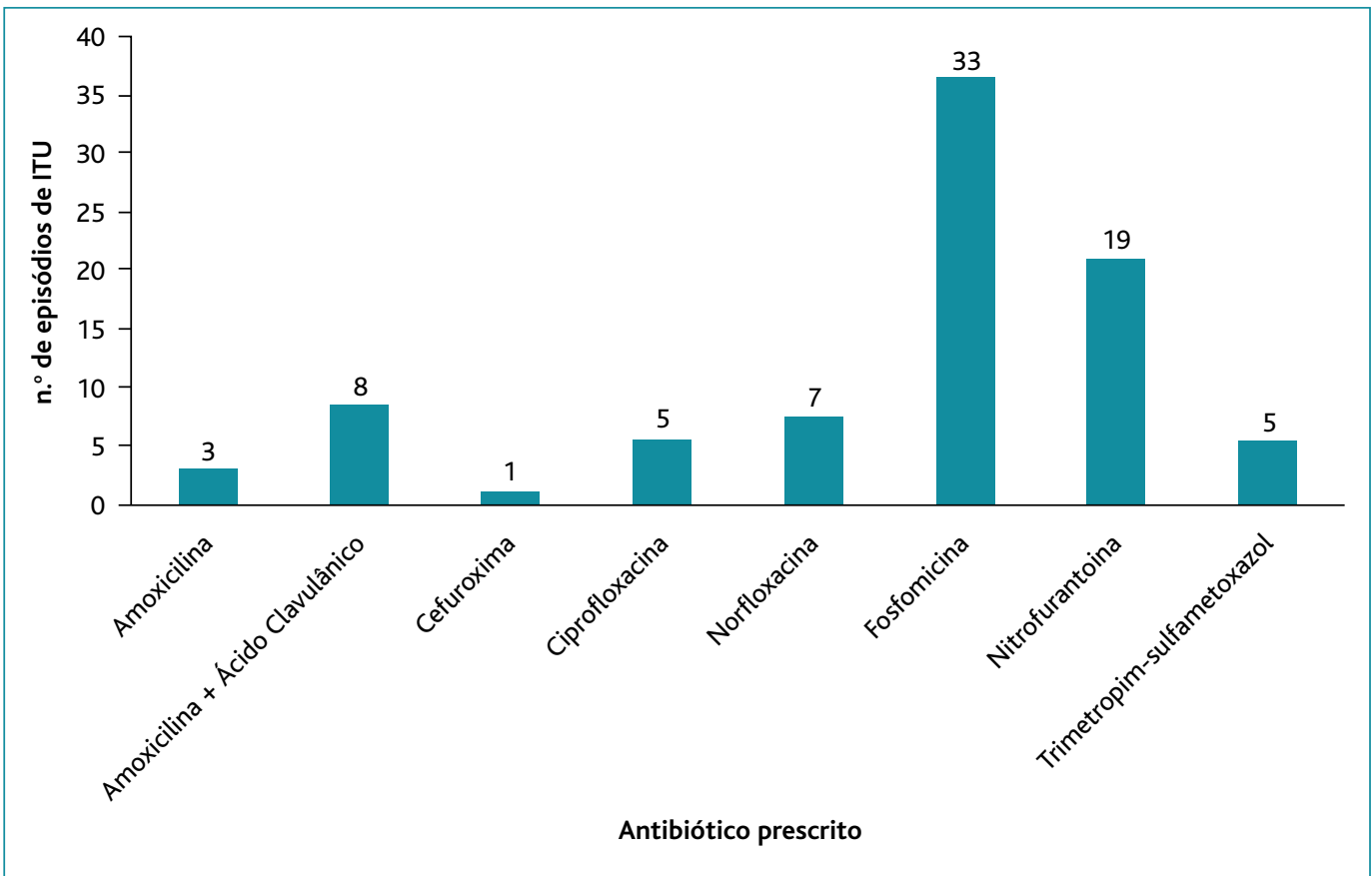

Figura 6. Distribuição dos antibióticos prescritos na Cistite Aguda Não Complicada em Mulher Não Grávida ( $\mathrm{N}=81$ )

tro isolamentos $(8,7 \%)$, a Klebsiella pneumoniae com três casos $(6,5 \%)$ e uma Pseudomonas aeruginosa (2,3\%). As bactérias Gram positivas representam $4,3 \%$, verificando-se um caso de Staphylococcus aureus $\mathrm{e}$ um caso de Streptococcus viridans. Num caso foi isolado agente etiológico mas este não foi especificado na folha de registo.

Das 46 uroculturas positivas, 42 eram provenientes do sexo fe-minino (91,3\%) e quatro do sexo masculino $(8,7 \%)$.

No Quadro III são representadas as prescrições de antibiótico por pedido e resultado da urocultura. Nos 29 episódios em que não foi feito o pedido de urocultura, foi prescrito antibiótico. Dos 75 casos em que foi pedida urocultura, em 68 casos houve presganismo mais frequente, tendo sido isolada em 35 casos, o que corresponde a $76,1 \%$ do total de uroculturas positivas. Seguiram-se o Proteus mirabilis com qua- crição de antibiótico, desconhecendo-se o antibiótico biótico ( $\mathrm{n}=97$ ), em 68 casos foi pedida urocultura, e dos em sete situações. Nos casos em que foi prescrito anti- 
quais em 42 casos foi isolado agente microbiológico.

Perfil de susceptibilidade aos antimicrobianos

Apesar de terem sido documentadas 46 uroculturas positivas, só há dados relativos a 43 antibiogramas.

Nestes casos em que houve confirmação microbiológica, a susceptibilidade antimicrobiana foi comparada com a terapêutica prescrita (Quadro IV).

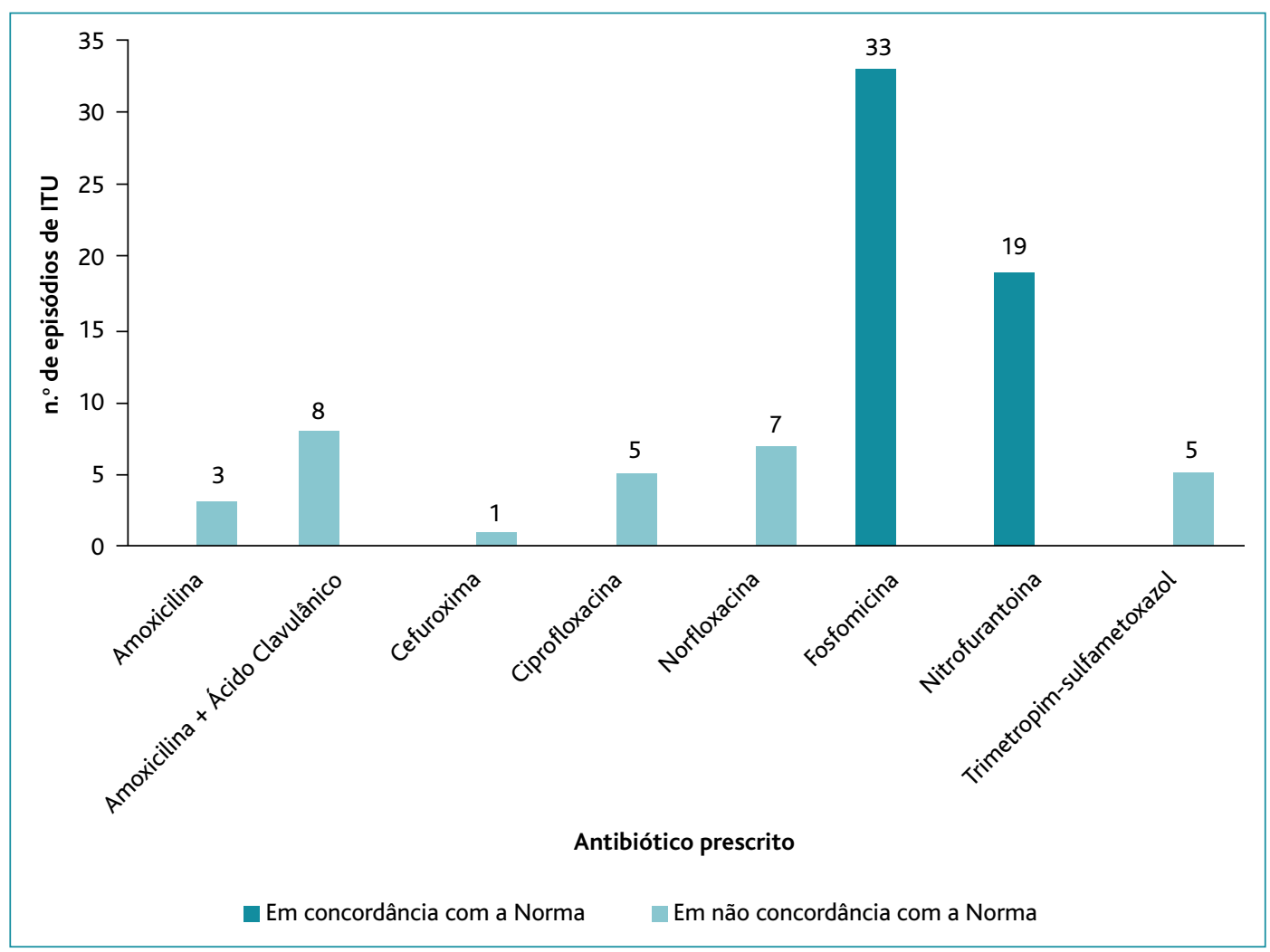

Em 23 antibiogramas o agente isolado era sensível ao antibiótico prescrito. Houve registo de seis casos de microrganismos resistentes ao antibiótico escolhido. Não houve registo do resultado do antibiograma em 14 casos.

Em 33 antibiogramas, o microrganismo isolado foi a E. coli. Pelo facto do número de antibiogramas registados ser diminuto e com o objectivo de optimizar os resultados, optou-se apenas por valorizar os antibiogramas em que o agente isolado foi a E.coli nas situações de Cistite Aguda Não Complicada em Mulher Não Grávida, o que corresponde a 24 episódios. Nestes casos, em 15 episódios o antibiograma mostrou que antibiótico prescrito era sensível e em um caso o antibiótico era resistente.

Oito resultados do antibiograma não foram registados. No Quadro V foi analisado o padrão de sensibilidade da E. coli para os episódios de Cistite Aguda Não Complicada em Mulher Não Grávida. Os antibióticos para os quais surgiram mais resistências foram o tri-

metroprim-sulfametoxazol e a amoxicilina, tendo sido reportados sete e cinco casos, respectivamente. Verificaram-se três casos de resistências à ampicilina e dois casos à amoxicilina com ácido clavulânico.

Não se encontrou nenhuma resistência para a fosfomicina ou para nitrofurantoína.

\section{DISCUSSÃO}

Este estudo baseou-se na análise de uma amostra de 104 episódios de ITU, identificados clínica e laboratorialmente por 38 médicos de Medicina Geral e Familiar, durante o período de três meses.

\section{Sexo e Idade}

A elevada prevalência de ITU encontrada na população feminina $(91,3 \%)$ está em concordância com a bibliografia. ${ }^{14}$ Esta situação é explicada pelas características anatómicas do sexo feminino. ${ }^{23}$

Mais de metade das ITU ocorreu em indivíduos com mais de 65 anos (57,6\%). Efectivamente, os idosos apre- 


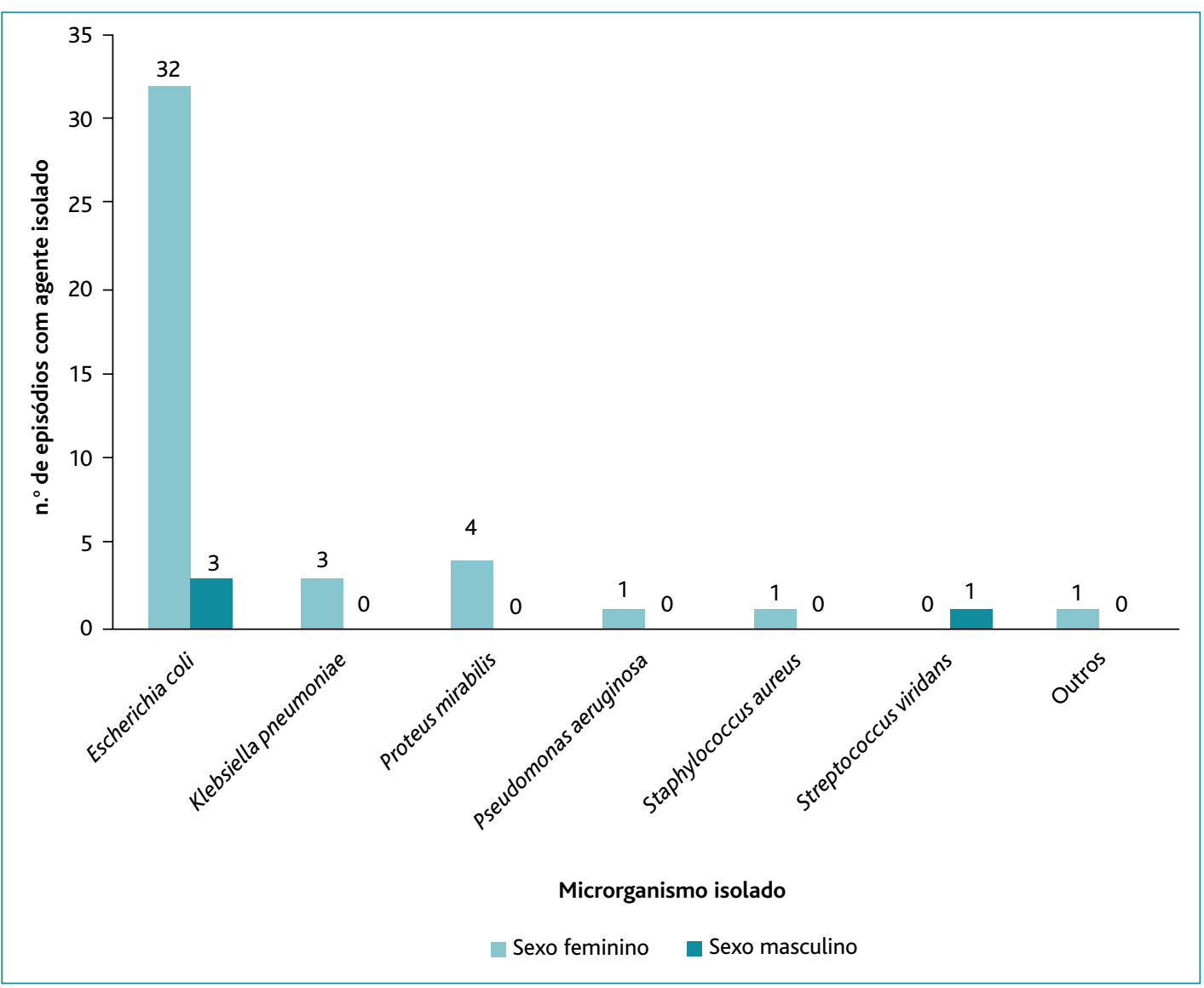

Figura 8. Distribuição das ITU por resultado da urocultura e sexo $(\mathrm{N}=46)$ va que mulheres pós-menopausa ou com diabetes controlada sem nefropatia poderão incluir-se nesta nomenclatura. ${ }^{25}$

Um estudo realizado na Holanda em 2010 refere que a maioria das ITU que surgem ao nível dos cuidados de saúde primários é não complicada, nomeadamente cistite aguda em mulheres adultas não grávidas. ${ }^{26} \mathrm{Nes}-$ te estudo, $81,7 \%$ de todos os episódios de ITU documentados correspondiam a episódios de Cistite Aguda Não Complicada em Mulher Não Grávida.

Apenas houve referência a um episódio de pielonefrite não complicada numa mulher com mais de 65 anos. Em média, por 28 casos de cistite aguda ocorre um episódio de pielonefrite. ${ }^{31}$ Czaja et al. verificaram que a incidência de pielonefrite era maior em mulheres jovens. $^{32}$

É frequente o aparecimento de ITU durante a gravidez. ${ }^{33}$ No presente estudo apenas foram identificados dois episódios de Cistite Aguda Não Complicada na Grávida e não houve registo de nenhum episódio de Bacteriúria Assintomática em Grávida. A identificação destas situações é importante, pois a presença de bacteriúria aumenta o risco de pielonefrite, de parto pré-termo e de recém-nascidos de baixo peso. ${ }^{34}$

A pesquisa de bacteriúria assintomática e o seu tratamento só está recomendado em grávidas (Grau de 


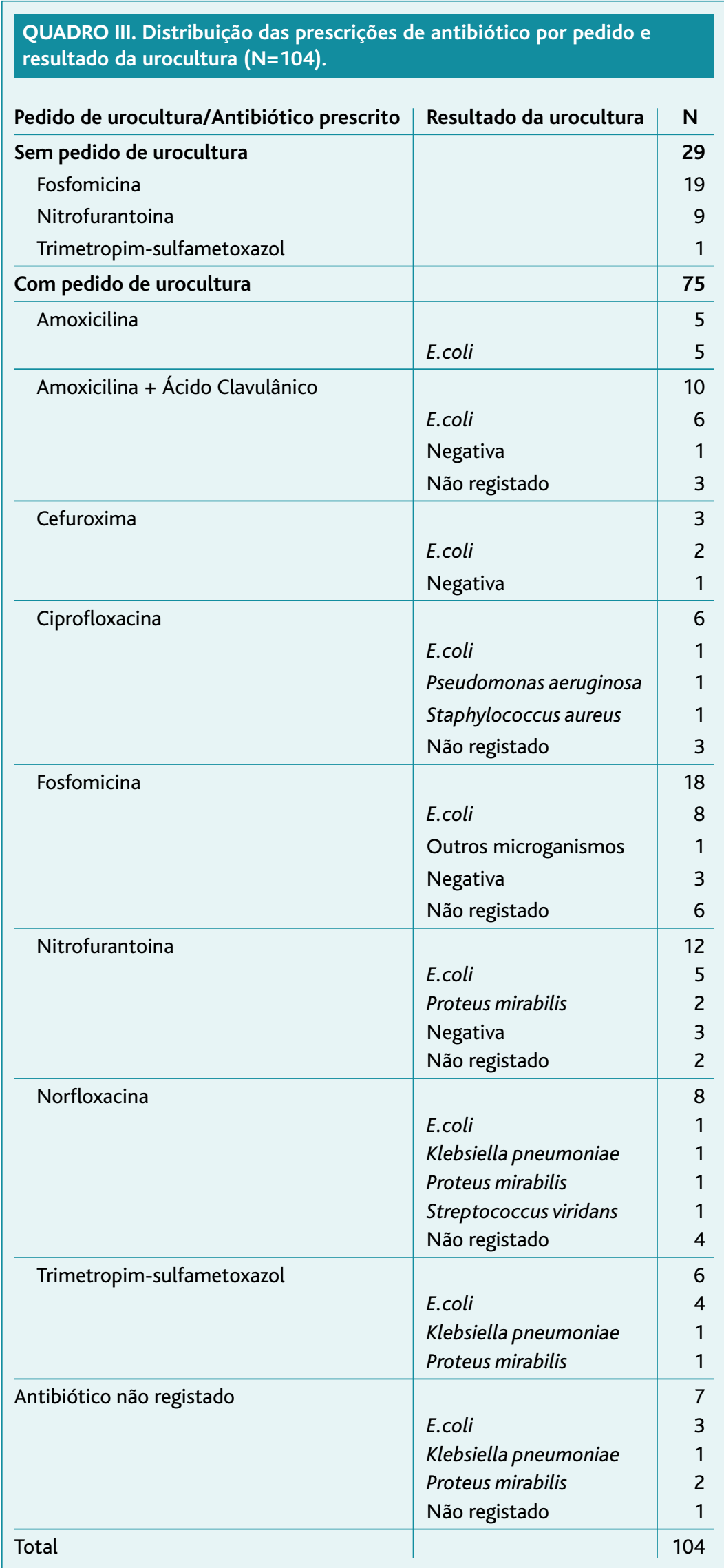

Evidência (GE): A-I) e candidatos a RTUP (GE: A-I) ou a outro procedimento urológico (GE: A-III). ${ }^{34}$

A bacteriúria assintomática também é um achado laboratorial comum em idosos, mas a sua pesquisa e tratamento não está recomendado nestas situações (GE: A-II). ${ }^{34}$

Foram identificados nove ITU no sexo masculino, cinco dos quais foram cistites. A Norma da DGS é pouco explícita quanto à abordagem das ITU no sexo masculino; contudo as ITU nos homens são raras e são geralmente classificadas como ITU complicadas. ${ }^{11}$

\section{Pedido de urocultura}

Foi feito o pedido de urocultura em $72,1 \%$ dos episódios de ITU encontrados.

Nos casos em que foi pedida urocultura, em pelo menos $77,3 \%$ este pedido não esteve em concordância com a Norma.

A urocultura é um exame importante para confirmar a presença de bacteriúria, identificar o agente etiológico e determinar a susceptibilidade aos diferentes antimicrobianos. ${ }^{18}$ Contudo, a urocultura não é necessária na maioria dos casos de ITU não complicada. . $^{14,16,35}$

Há estudos que admitem que a melhor opção custo-benefício é tratar todos os indivíduos sintomáticos, sem a realização de outros procedimentos, porém estes estudos não tiveram em consideração o aumento das resistências aos antibióticos que daí pode advir. ${ }^{36-37}$

O elevado número de uroculturas pedidas poder-se-á explicar pela adopção de medidas que garantam uma escolha mais adequada, caso se verifique persistência da sintomatologia. O questionário era omisso quanto à situação de recidiva/recorrência das ITU, o que 
QUADRO IV. Resultado do antibiograma por agente isolado ( $N=43)$.

\begin{tabular}{l|c|c|c|c}
\multirow{2}{*}{} & \multicolumn{3}{|c|}{ Sensibilidade do microrganismo } & \\
\cline { 2 - 5 } & Sensível & Resistente & Sem resultado & N \\
\hline Antibiogramas em que foi isolada E. coli & 21 & 2 & 10 & 33 \\
\hline $\begin{array}{l}\text { Antibiogramas em que foram isolados } \\
\text { outros agentes que não E. coli }\end{array}$ & 2 & 4 & 4 & 10 \\
\hline & 23 & 6 & 14 & 43
\end{tabular}

QUADRO V. Percentagem de susceptibilidade da E.coli nos episódios de Cistite Aguda Não Complicada em Mulher Não Grávida.

Antibiótico testado

\begin{tabular}{l|c|c|c|c|} 
& Sensível & Intermédio & Resistente & N \\
\hline Cefotaxima & 3 & & & 3
\end{tabular}

\begin{tabular}{l|r|r|r|r}
\hline Cefotaxima & 3 & & 3 & 100 \\
\hline Cefoxitina & 1 & & 1 & 100 \\
\hline Ceftazidima & 1 & & 1 & 100 \\
\hline Ceftriaxona & 1 & & 1 & 100 \\
\hline Fosfomicina & 4 & & 4 & 100 \\
\hline Gentamicina & 11 & & 11 & 100 \\
\hline
\end{tabular}

\begin{tabular}{l|l}
\hline Nitrofurantoína & 21 \\
\hline
\end{tabular}

Ofloxacina

\begin{tabular}{l|l}
\hline Amicacina & \\
\hline Norfloxacina & 16
\end{tabular}

\begin{tabular}{l|l}
\hline Ciprofloxacina & 11 \\
\hline Cefuroxima & 9 \\
\hline
\end{tabular}

Amoxicilina+Ácido clavulânico 16

Amoxicilina

Trimetroprim-sulfametoxazol

Cefalotina

Cefradina

Ampicilina

pode justificar o excessivo pedido de uroculturas.

\section{Antibioterapia}

Em 71,2\% dos episódios de ITU o tratamento foi empírico, prévio ao resultado da urocultura. Esta situação, por um lado, reflecte um pedido excessivo de uroculturas, mas, por outro lado, está descrito que a instituição precoce do tratamento antimicrobiano é a forma mais eficaz de diminuir a morbilidade e mortalidade as- sociadas as ITU. ${ }^{13}$

Na maioria das ITU identificadas foi prescrito antibiótico (93,3\%). A fosfomicina e a nitrofurantoína foram os antibióticos mais prescritos.

Nas situações de Cistite Aguda Não Complicada em Mulher Não Grávida, mais de metade da terapêutica prescrita $(64,2 \%)$ esteve em concordância com a Norma. Nos restantes episódios o antibiótico escolhido aparentemente não foi o mais adequado. Contudo, poderão ter existido outros motivos clínicos que justificaram essa escolha.

Apesar das terapêuticas de primeira linha não serem as mesmas em todos os países, há estudos que mostram percentagens menores de prescrição dos antibióticos de primeira linha, $17,5 \%$ e $37 \%$ num estudo espanhol e irlandês, respectivamente. ${ }^{9,38}$

Foi prescrita nitrofurantoína em 23,5\%. A elevada eficácia da nitrofurantoína na Cistite Aguda Não Complicada em Mulher Não Grávida e o facto de haver poucas resistências à E. coli e poucos efeitos adversos faz deste fármaco uma opção adequada para estas situações (GE: A-I). ${ }^{25}$

A fosfomicina foi utilizada em $40,7 \%$ episódios de cistite aguda não complicada em mulher não grávida. Apesar de se verificarem taxas de erradicação bacteriana inferiores a outros antibióticos, é considerada um 
fármaco de primeira linha na cistite aguda não complicada (GE: A-I). ${ }^{25}$ Também parecem existir elevadas percentagens de susceptibilidade à fosfomicina. ${ }^{25}$

No tocante à posologia, a nitrofurantoína deverá ser administrada de seis em seis horas durante cinco a sete dias e o tratamento com fosfomicina consta apenas de uma única administração, o que é altamente vantajoso. ${ }^{28}$

Os beta-lactâmicos foram usados em 14, 8\% na Cistite Aguda Não Complicada em Mulher Não Grávida. Embora sejam frequentemente usados, alguns autores mostraram que estes fármacos tendem a ser menos eficazes e como tal não devem ser usados como terapêutica de primeira linha na cistite. ${ }^{25} \mathrm{~A}$ Norma admite o uso de amoxicilina com ácido clavulânico se os antibióticos de primeira linha não estiverem disponíveis ou caso o seu uso esteja contraindicado (GE: B-I) ${ }^{28}$

Em 6,2\% das situações foi prescrito trimetroprimsulfametoxazol, antibiótico muito eficaz no tratamento de cistite aguda não complicada. Contudo, a Sociedade Europeia de Urologia não aconselha o uso de trimetropim-sulfametoxazol como terapêutica de primeira linha, a menos que as resistências locais da E. coli sejam inferiores a $20 \% .{ }^{33} \mathrm{O}$ estudo ECO•SENS mostra que em Portugal a resistência da E. coli ao trimetropimsulfametoxazol é superior a $20 \% .^{22}$

As fluroquinolonas foram prescritas em 14,8\% dos casos. Apesar de poderem ser eficazes, o seu uso deve ser reservado para segunda linha e para o tratamento de infecções complicadas ou nosocomiais, já que se tem verificado um aumento das resistências nos países onde o seu uso é mais difundido. ${ }^{25}$ Portugal apresenta uma elevada taxa de uso de quinolonas, ${ }^{4}$ facto que poderá explicar as altas percentagens de resistência registadas por outros autores. ${ }^{23-24}$

Relativamente ao único episódio de pielonefrite, o antibiótico instituído foi o trimetropim-sulfametoxazol. As orientações internacionais prevêem o uso deste antibiótico como fármaco de primeira linha na pielonefrite apenas se a bactéria for sensível ${ }^{25} \mathrm{O}$ antibiótico recomendado pela Norma para os episódios de pielonefrite ligeira a moderada é o ceftriaxone, seguido de cefuroxima-axetil.

Nos dois episódios de Cistite Aguda Não Complicada em Mulher Grávida, foi prescrita fosfomicina, o que está em consonância com o que a Norma propõe. Todas as situações de bacteriúria assintomática ou de cis- tite identificadas em grávidas devem ser tratadas com fosfomicina ou com amoxicilina com ácido clavulânico (GE: A-III). ${ }^{28}$

A escolha da terapêutica antimicrobiana, para além da eficácia e do padrão de susceptibilidade dos microrganismos, deve ter em consideração a tolerância, os efeitos adversos, os custos, a disponibilidade dos fármacos e ainda as alergias e adesão dos indivíduos. ${ }^{33,25}$

\section{Resultado da urocultura}

A urocultura foi positiva em 82,1\% das situações em que se obteve um resultado. Esta situação poderá estar relacionada com o facto da maioria dos episódios de ITU identificados apresentarem sinais e sintomas muito sugestivos. A capacidade de diagnóstico com base na sintomatologia apresenta uma sensibilidade variável. ${ }^{39-40}$ Quanto maior o número de sintomas encontrados maior a probabilidade da urocultura ser positiva. ${ }^{15}$

A distribuição percentual dos agentes etiológicos para ITU da comunidade foi semelhante ao verificado por outros autores portugueses e estrangeiros.,17,20,22-24

Como esperado, a E. coli foi o microrganismo mais frequentemente isolado nos exames culturais $(76,1 \%)$. A E. colié responsável por 75-95\% dos episódios de ITU não complicada. ${ }^{17}$

Em relação às outras enterobactérias, Martins et al verificaram uma prevalência ligeiramente diferente para o Proteus mirabilis e a Klebsiella pneumoniae. ${ }^{23} \mathrm{~A}$ importância do Proteus mirabilis e da Klebsiella pneumoniae na patogénese das ITU não deve ser subestimada, já que em Portugal as suas prevalências parecem ser maiores do que no resto da Europa. ${ }^{3}$

Apesar da Pseudomonas aeruginosa ter sido isolada em apenas um caso, a sua importância não deve ser menosprezada, dado que vários estudos mostram a sua emergência na comunidade nos últimos anos, embora na maioria das vezes se comporte como um microrganismo nosocomial. ${ }^{13,30,41}$

\section{Perfil de susceptibilidade aos antimicrobianos}

Do total de antibiogramas registados, apenas em seis episódios o microrganismo era resistente ao antibiótico prescrito. Vários estudos mostram que nem sempre os resultados clínicos estão em consonância com os resultados do antibiograma e que pode haver cura clínica e microbiológica mesmo utilizando um antibiótico 
que se revelou resistente no antibiograma. ${ }^{14}$

A E. coli mostrou sensibilidade variável aos diferentes antimicrobianos. Neste estudo não se encontrou nenhum caso de resistência à fosfomicina ou à nitrofurantoína. Na maioria dos países, os microrganismos responsáveis por cistite aguda não complicada em mulheres têm-se mantido susceptíveis a estes antibióticos, apesar de se verificarem padrões de susceptibilidade variáveis. ${ }^{17} \mathrm{O}$ estudo ECO•SENS mostrou a existência de uma baixa incidência de resistências à fosfomicina e à nitrofurantoína, apesar de serem fármacos muito usados e há bastante tempo em vários países. Isto parece estar relacionado com o facto de estes antibióticos serem quase de uso exclusivo nas ITU., ${ }^{3,22}$

No nosso estudo verificaram-se percentagens baixas de susceptibilidade da E. coli à amoxicilina $(61,5 \%)$ e à ampicilina (25,0\%). A resistência às penicilinas correlaciona-se com a alta prevalência de beta-lactamases, ${ }^{5}$ por este motivo o seu uso não está recomendado como terapêutica de primeira linha. Apesar disso há locais em que a sua prescrição pode ser considerada, tendo em conta o padrão local de resistências. ${ }^{14}$ Para a amoxicilina com ácido clavulânico obtiveram-se níveis de susceptibilidade superiores $(84,2 \%)$ e comparáveis a outros estudos. ${ }^{23-24}$

O trimetropim-sulfametoxazol foi o antibiótico para o qual foram registados mais casos de resistências, apresentando uma sensibilidade de $61,1 \%$. O padrão de resistência do trimetropim-sulfametoxazol é muito variável de país para país e dentro da mesma região. $\mathrm{O}$ mesmo estudo ECO•SENS mostra que Portugal é o país da Europa com maiores taxas de resistência a este antibiótico $(26,7 \%)$, por oposição à Finlândia $(4,9 \%) .{ }^{3,22} \mathrm{Na}$ maioria dos países europeus a percentagem de resistências é superior a $20 \%$, pelo que o seu uso é desaconselhado como terapêutica empírica. ${ }^{25}$ Estudos portugueses no âmbito das ITU da comunidade mostram percentagens de susceptibilidade superiores ao nosso estudo. ${ }^{23-24}$

A percentagem de susceptibilidade à ciprofloxacina e norfloxacina foi respectivamente $91,7 \%$ e $94,1 \%$, o que não está em consonância com estudos maiores que têm mostrado que, em Portugal, a resistência à ciprofloxacina é mais alta do que na maioria dos países europeus. ${ }^{22}$ Os padrões de resistência da $E$. coli às fluroquinolonas são muito variáveis, mas tem-se constatado um aumento progressivo das resistências. ${ }^{17}$ Assim, o seu uso como terapêutica empírica só deverá ser recomendado se as taxas de resistências locais forem inferiores a $10 \% .^{25}$

Os resultados apresentados neste trabalho devem ser interpretados com prudência, dado não serem representativos da população em geral. Pode-se considerar como limitação a este estudo o pequeno número de episódios de ITU recolhidos. Seria desejável que as uroculturas e os antibiogramas tivessem sido realizados no mesmo laboratório e para os mesmos antibióticos, para poder haver uma maior fiabilidade dos resultados.

O aparecimento de microrganismos resistentes aos antibióticos mais frequentemente usados nas ITU é um facto, daí que a realização de estudos sobre os padrões de sensibilidade aos antimicrobianos tenha a maior importância para produzir as recomendações mais adequadas ao tempo e lugar. É essencial conhecer a realidade da terapêutica para ITU na comunidade para se poder melhorar a prática clínica.

\section{AGRADECIMENTOS}

Os autores agradecem aos médicos de medicina geral e familiar cuja participação foi indispensável na recolha de dados.

\section{REFERÊNCIAS BIBLIOGRÁFICAS}

1. European Centre for Disease Prevention and Control. Annual epidemiological report: reporting on 2009 surveillance data and 2010 epidemic intelligence data. ECDC; 2011 [cited 2014 Feb 20]. Available from: http://ecdc.europa.eu/en/ publications/Publications/1111_SUR_Annual_Epidemiological_Report_on_Communicable_Diseases_in_Europe.pdf

2. Direcção-Geral da Saúde. Orientação da Direcção-Geral da Saúde $n^{\circ}$ 029/2011 de 05/08/2011 (atualização de 24/08/2011): princípios gerais de anti-bioterapia. Lisboa: DGS; 2011 [cited 2014 Feb 23]. Available from: http://www.dgs.pt. Portuguese

3. Kahlmeter $\mathrm{G}$. Prevalence and antimicrobial susceptibility of pathogens in uncomplicated cystitis in Europe. The ECO.SENS study. Int J Antimicrob Agents. 2003;22 Suppl 2:49-52.

4. European Surveillance of Antimicrobial Consumption. Final management report 2009-2010. ESAC; 2011 [cited 2014 Feb 23]. Available from: http://www.esac.ua.ac. be/main.aspx?c= ${ }^{*} E S A C 2 \& n=50031$

5. European Centre for Disease Prevention and Control. Antimicrobial resistance surveillance in Europe: annual report of the European Antimicrobial Resistance Surveillance Network (EARS-Net). ECDC; 2010 [cited 2014 Feb 23]. Available from: http://ecdc.europa.eu/en/publications/Publications/1111_SUR_AMR_data.pdf

6. Cars O, Mölstad S, Melander A. Variation in antibiotic use in the European Union. Lancet. 2001;357(9271):1851-3. 
7. Butler CC, Dunstan F, Heginbothom M, Mason B, Roberts Z, Hillier S, et al. Containing antibiotic resistance: decreased antibiotic-resistant coliform urinary tract infections with reduction in antibiotic prescribing by general practices. Br J Gen Pract. 2007;57(543):785-92.

8. Hummers-Pradier E, Ohse AM, Koch M, Heizmann WR, Kochen MM. Management of urinary tract infections in female general practice patients. Fam Pract. 2005;22(1):71-7.

9. Llor C, Rabanaque $\mathrm{G}$, López A, Cots JM. The adherence of GPs to guidelines for the diagnosis and treatment of lower urinary tract infections in women is poor. Fam Pract. 2011;28(3):294-9.

10. Programa Nacional de Controlo de Infecção. Inquérito nacional de prevalência de infecção nosocomial. Lisboa: Instituto Nacional de Saúde Dr. Ricardo Jorge; 2009.

11. Hooton TM. Pathogenesis of urinary tract infections: an update. J Antimicrob Chemother. 2000; 46 Suppl 1:1-7.

12. Foxman B, Barlow R, d'Arcy H, Gillespie B, Sobel JD. Urinary tract infection: self-reported incidence and associated costs. Ann Epidemiol. 2000;10(8):509-15.

13. Andreu A, Alós Jl, Gobernado M, Marco F, de la Rosa M, García-Rodríguez JA. Etiología y sensibilidad a los antimicrobianos de los uropatógenos causantes de la infección urinaria baja adquirida en la comunidad: estudio nacional multicéntrico. Enferm Infecc Microbiol Clin. 2005;23(1):4-9. Spanish

14. Hummers-Pradier $E$, Kochen MM. Urinary tract infections in adult general practice patients. Br J Gen Pract. 2002;52(482):752-61.

15. Mclsaac WJ, Low DE, Biringer A, Pimlott N, Evans M, Glazier R. The impact of empirical management of acute cystitis on unnecessary antibiotic use. Arch Intern Med. 2002;162(5):600-5.

16. Stamm WE, Hooton TM. Management of urinary tract infections in adults. N Engl J Med. 1993;329(18):1328-34.

17. Naber KG, Schito G, Botto H, Palou J, Mazzei T. Surveillance study in Europe and Brazil on clinical aspects and Antimicrobial Resistance Epidemiology in Females with Cystitis (ARESC): implications for empiric therapy. Eur Urol. 2008;54(5):1164-75.

18. Hooton TM. Uncomplicated urinary tract infection. N Engl J Med. 2012;366(11):1028-37.

19. Winstanley TG, Limb DI, Eggington R, Hancock F. A 10 year survey of the antimicrobial susceptibility of urinary tract isolates in the UK: the Microbe Base project. J Antimicrob Chemother. 1997;40(4):591-4.

20. Andreu A, Planells I, Grupo Cooperativo Español para el Estudio de la Sensibilidad Antimicrobiana de los Patógenos Urinarios. Etiología de la infección urinaria baja adquirida en la comunidade y resistencia de Escherichia coli a los antimicrobianos de primera línea: estudio nacional multicéntrico. Med Clin (Barc). 2008;130(13):481-6. Spanish

21. Gupta K, Sahm DF, Mayfield D, StammWE.Antimicrobial resistance among uropathogens that cause community-acquired urinary tract infections in women: a nationwide analysis. Clin Infect Dis. 2001;33(1):89-94.

22. Kahlmeter G.An international survey of the antimicrobial susceptibility of pathogens. J Antimicrob Chemother. 2003;51(1):69-76.

23. Martins F, Vitorino J,Abreu A. Avaliação do perfil de suscetibilidade aos antimicrobianos de microrganismos isolados em urinas na Região do Vale do Sousa e Tâmega. Acta Med Port. 2010;23(4):641-6. Portuguese.

24. Correia C, Costa E, Peres A, Alves M, Pombo G, Estevinho L. Etiologia das infeções do tracto urinário e sua suscetibilidade aos antimicrobianos. Acta Med Port. 2007;20(6):543-50. Portuguese.
25. Gupta K, Hooton TM, Naber KG, Wullt B, Colgan R, Miller LG, et al. International clinical practice guidelines for the treatment of acute uncomplicated cystitis and pyelonephritis in women: a 2010 update by the Infectious Disease Society of America and the European Society for Microbiology and Infectious Diseases. Clin Infect Dis. 2011;52(5): e103-20.

26. Lugtenberg M, Burgers JS, Zegers-van Schaick JM, Westert GP. Guidelines on uncomplicated urinary tract infections are difficult to follow: perceived barriers and suggested interventions. BMC Fam Pract. 2010; 11:51.

27. Kahan NR, Chinitz DP, Waitman DA, Kahan E. Empiric treatment of uncomplicated UTI in women: wasting money when more is not better.J Clin Pharm Ther. 2004;29(5):437-41.

28. Direç̧ão-Geral da Saúde. Terapêutica das infecções do aparelho urinário (comunidade). Norma $n^{\circ}$ 026/2011, de 30/08/2011. Lisboa: DGS; 2013 [cited 2014 Feb 2]. Available from: http://www.dgs.pt. Portuguese.

29. Foxman B. Epidemiology of urinary tract infections: incidence, morbidity, and economic costs. Am J Med. 2002;113 Suppl 1A:5S-13S.

30. Ochoa Sangrador C, Eiros Bouza JM, Mendez CP, Inglada Galiana L. Etiología de las infecciones del tracto urinario y sensibilidad de los uropatógenos a los antimicrobianos. Rev Esp Quimioterap. 2005;18(2):124-35. Spanish.

31. Ikäheimo R, Siitonen A, Heiskanen T, Kärkkäinen U, Kuosmanen P, Lipponen $P$, et al. Recurrence of urinary tract infection in a primary care setting: analysis of a 1-year follow-up of 179 women. Clin Infect Dis. 1996;22(1): 91-9.

32. Czaja CA, Scholes D, Hooton TM, Stamm WE. Population-based epidemiologic analysis of acute pyelonephritis. Clin Infect Dis. 2007;45(3): 273-80.

33. Grabe M, Bishop MC, Bjerklund-Johansen TE, Botto H, Çek M, Lobel B, et al. Guidelines on urological infections.Arnhem: European Association of Urology; 2009.

34. Nicolle LE, Bradley S, Colgan R, Rice JC, Schaeffer A, Hooton TM. Infectious iseases Society of America guidelines for the diagnosis and treatment of asymptomatic bacteriuria in adults. Clin Infect Dis. 2005;40(5):643-54.

35. Wilson ML, Gaido L. Laboratory diagnosis of urinary tract infections in adult patients. Clin Infect Dis. 2004;38(8):1150-8.

36. Barry HC, Ebell MH, Hickner J. Evaluation of suspected urinary tract infection in ambulatory women: a cost-utility analysis of office-based strategies. J Fam Pract. 1997;4(1):49-60.

37. Fenwick EA, Briggs AH, Hawke $\mathrm{Cl}$. Management of urinary tract infection in general practice: a cost-effectiveness analysis. $\mathrm{Br} J$ Gen Pract. 2000;50(457):635-9.

38. Vellinga A, Cormican M, Hanahoe B, Bennett K, Murphy AW. Antimicrobial management and appropriateness of treatment of urinary tract infection in general practice in Ireland. BMC Fam Pract. 2011;12(1):108.

39. Bent S, Nallamothu BK, Simel DL, Fihn SD, Saint S. Does this woman have an acute uncomplicated urinary tract infection? JAMA. 2002;287 (20):2701-10.

40. Schmiemann G, Kniehl E, Gebhardt K, Matejczyk MM, Hummers-Pradier E. The diagnosis of urinary tract infection: a systematic review. Dtsch Arztebl Int. 2010;107 (21):361-7.

41. Rodriguéz López FC, Franco-Alvarez de Luna F, Gordillo Urbano RM, Ibarra González A, Casal Román M. Microorganismos aislados de muestras de 
orina procedentes de la comunidad y padrón de sensibilidad en un período de 12 años. Rev Esp Quimioterap. 2005;18 (2):159-67.

\section{CONFLITOS DE INTERESSE}

Inês Vilas-Boas Tavares declara não possuir qualquer tipo de conflitos de interesse. Armando Brito de Sá é co-autor da "Norma da Direç̧ão-Geral da Saúde n 015/2011, de 30 de Agosto de 2011,"Terapêutica das infecções do aparelho urinário (comunidade)", em foco no presente estudo.

\author{
ENDEREÇO PARA CORRESPONDÊNCIA \\ Inês Vilas-Boas Tavares \\ Rua Sam Levy, $n^{\circ} 1$, edifício O, r/c esq \\ 1400-391 Lisboa \\ E-mail: inesvbtavares@gmail.com
}

Recebido em 09-04-2013

Aceite para publicação em 23-02-2014

\section{ABSTRACT}

\section{ANTIMICROBIAL PRESCRIBING FOR URINARY TRACT INFECTION IN PRIMARY HEALTH CARE}

Objectives: The objectives of this study were to assess the prescription of antibiotics for urinary tract infection (UTI) in general practice, the degree of agreement with the Directorate General for Health guidelines for treatment of urinary tract infections in the community, to identify the infecting microorganisms, and to determine their susceptibility to antibiotics.

Type of study: Cross-sectional study.

Location: Family Health Units of Lisbon and Vale do Tejo, Portugal.

Population: Patients 18 years of age and older with a clinical and/or laboratory diagnosis of UTI

Material and Methods: Thirty-eight family physicians collected data between November 2011 and January 2012. We obtained a non-random sample of 104 episodes of UTI in patients aged 18 years and older. Variables studied were gender, age, type of UTI, request for urine culture, choice of antibiotics based on urine culture results, antibiotic prescriptions, urine culture results and antimicrobial susceptibility.

Results: Acute uncomplicated cystitis in non-pregnant women was the most common type of UTI (81,7\%). Urine cultures were requested in $72,1 \%$ of cases. Antibiotics were prescribed in $93,3 \%$ of cases, with fosfomycin $(38,1 \%)$ and nitrofurantoin $(21,6 \%)$ the most common antibiotics prescribed. For acute uncomplicated cystitis in non-pregnant women we found that antibiotic prescription was in line with the guideline in $64,2 \%$ of cases. The urine culture was positive in $82,1 \%$ of cases and $E$. coli was isolated in $76,1 \%$ of these. No bacterial resistance to fosfomycin or nitrofurantoin was reported.

Conclusions: In most episodes of UTI an appropriate prescription was chosen consistent with current guidelines. E. coli was the most prevalent microorganism isolated and showed a high susceptibility to fosfomycin and nitrofurantoin.

Key-words: Urinary Tract Infection; Antibiotics; Antimicrobial Resistance.

\section{ANEXO I \\ INSTRUMENTO DE RECOLHA DE DADOS}

Este estudo visa recolher dados sobre a realidade de Prescrição de Antimicrobianos para as Infecções do Tracto Urinário nos Cuidados de Saúde Primários.

A colheita de dados decorre durante os meses de Novembro, Dezembro de 2011 e Janeiro de 2012. A população em estudo compreende todos os indivíduos com idade igual ou superior a 18 anos. O preenchimento dos dados poderá ser efectuado em diferentes circunstâncias:

- Numa só consulta, quando o episódio fique resolvido (terapêutica empírica sem outro tipo de intervenção);

- Em duas ou mais consultas (início de sintomatologia e regresso para mostrar resultado do antibiograma);

- Retrospectivamente (situações em que o doente traz urocultura).

Em caso de dúvida contactar Inês Tavares: 915931679 
Data____ _

Unidade de Saúde

\section{Folha de registo de dados das Infecções do Tracto Urinário}

Para cada episódio de Infecção do Tracto Urinário preencha os seguintes dados com uma cruz $(X)$. Em cada alínea seleccione apenas uma opção.

1. Sexo: Feminino $\square$ Masculino $\square$

2. Idade

3. Tipo de Infecção Urinária

Cistite aguda não complicada em mulher não grávida

Cistite aguda não complicada em mulher grávida

Pielonefrite - casos ligeiros a moderados

Bacteriúria assintomática em grávidas

$\square$ Bacteriúria assintomática em candidatos a RTU-P (ressecção trans-uretral da próstata)

Outros (especifique)
4. Pedido de urocultura $\operatorname{Sim} \square \quad$ Não

5. Antibioticoterapia baseada no resultado da urocultura Sim $\square$ Não $\square$

6. Qual o primeiro antibiótico que foi prescrito? - nome comercial ou princípio activo. Deixe em branco caso não tenha sido prescrito antibiótico neste episódio de doença. (preencha de forma legível e com maiúsculas)

7. Resultado da urocultura

\begin{tabular}{|l|}
\hline Microrganismo isolado \\
\hline Negativa \\
\hline Escherichia coli \\
\hline Pleteus mirabilis \\
\hline Enterococcus faecalis \\
\hline Pseudomonas aeruginosa \\
\hline Staphylococcus saprophyticus \\
\hline Outro (especifique)
\end{tabular}

8. Se foi pedido antibiograma, assinale o padrão de susceptibilidade para os seguintes antibióticos:

\begin{tabular}{|l|l|l|l}
\hline Antibiótico testado & Sensível & Intermédio & Resistente \\
\hline Amoxicilina & & & \\
\hline Amoxicilina + Ácido clavulânico & & & \\
\hline Ampicilina & & & \\
\hline Ceftazidima & & & \\
\hline Cefotaxima & & & \\
\hline Cefoxitina & & & \\
\hline Ceftriaxona & & & \\
\hline Ciprofloxacina & & & \\
\hline Fosfomicina & & & \\
\hline Gentamicina & & & \\
\hline Levofloxacina & & & \\
\hline Nitrofurantoína & & & \\
\hline Norfloxacina & & & \\
\hline Ofloxacina & & & \\
\hline Piperacilina & & & \\
\hline Tazobactam & & & \\
\hline Tobramicina & & & \\
\hline Trimetroprim-sulfametoxazol & & & \\
\hline Vancomicina & & & \\
\hline Outro (especifique) & & \\
\hline
\end{tabular}

Obrigado pela sua colaboração. Inês VB Tavares - Aluna do $6^{\circ}$ ano da FMUL 